\title{
Healthcare resources to care for spinal conditions: international experience (a systematic scoping review)
}

\author{
A.K. Dulaev ${ }^{1,2}$, D.I. Kutianov ${ }^{1}$, P.V. Zhelnov ${ }^{1}$, S.L. Brizhan'1 \\ ${ }^{1}$ Pavlov First St. Petersburg State Medical University, Saint Petersburg, Russian Federation \\ ${ }^{2}$ Saint-Petersburg I.I. Dzhanelidze Research Institute of Emergency Medicine, Saint Petersburg, Russian Federation
}

\begin{abstract}
Objective Review emerging trends within healthcare sectors internationally to care for spinal conditions in developed Western European and North American countries. Material and methods An explorative review of electronic bibliographic (Scopus, Pubmed, etc.), thesis and dissertation database, organization websites, grey literature resources and reference lists of relevant papers was undertaken to identify the key publication outlets for relevant content between 2016 to 2020 . In the present review, the depth of the search was 27 years (post 1994). This review utilized a methodology structured using the Preferred Reporting Items for Systematic Reviews and Meta-Analyses (PRISMA-ScR and PRISMA-S preprint) checklist with the description available on https://doi.org/10.17605/OSF. IO/5JGN4. Results The researchers explored the conditions for strong primary spine care providing effective measures and strategies in streamlining patients and examined the appropriateness of referrals for high-technology imaging assessment. Primary care with its integrative function is provided by professionals with specialized training including general practitioners and nurses. Guidance on the management and standards of inpatient care for a diverse and complex range of conditions are of concern with a focus on specialized spinal services providing invasive management strategies for traumatic spinal cord injuries, in particular. Direct access to diagnostic procedures is essential at specialised spinal services providing conservative and surgical management for a acute spinal diseases with the decision making process and care for this group of patients being very complex with little support of evidence based medicine sources. Conclusion Significant input from clinical and support services is required to provide clinical practice guidelines based upon the best available research evidence and practice experience with a greater range of approaches and techniques.
\end{abstract}

Keywords: spine disease, health care system, triage, general practitioner, nursing personnel, diagnostic radiology, surgical treatment, spine surgery

\section{INTRODUCTION}

The performance of health systems for spinal diseases accompanied by neurological disorders and pain relative to traumatic spinal cord injury needs improvements to achieve health goals [1]. The rationale and importance of developing a sustainable evidence-based model of care can be seen with an instance from countries with advanced economies [2, 3].From a practical point of view three major aspects can be identified to determine complexity of the issue. First, there is a variety of spinal nosologies and scarce information on the spatial distribution of morbidity [4] due to the absence of representative information on nontraumatic spinal cord injury to be accurately recorded in the existing spinal cord injury registries [5]. Involvement of the vertebral column is seen as the primary cause of the spinal disorder in the patients rather than involvement of the vascular and nervous structures [6]. Both neurosurgeons and orthopedic surgeons specializing in spine surgery are skilled in taking care of the conditions. The social and economic burdens experienced by patients with spinal disorders and their caregivers can be substantial. Greater attention is urgently needed to mitigate this increasing burden and the impact it is having on health and social systems $[7,8]$.

The purpose of the study was to review emerging trends within healthcare sectors internationally to care for spinal conditions in developed Western European and North American countries.

\section{MATERIAL AND METHODS}

The term economically advanced country was used in the article to designate nations that enjoy high per capita income, high standards of living as classified by United Nations [9] and the World Bank [10] recognizing the persistence and accuracy of the data provided. This review was performed with a scoping approach utilizing a methodology structured using the Preferred Reporting Items for Systematic Reviews and Meta-Analyses (PRISMA-ScR [11] and PRISMA-S [12] preprint) checklist with the description available on the Open Science Framework (OSF) web platform at https://doi.org/10.17605/OSF. IO/5JGN4.

An explorative review undertaken between 2016 and 2020 relied on:

- mostly on bibliographic databases including Scopus, PubMed, Google Scholar, Cochrane Library, Centre for Reviews and Dissemination (https://www. 
york.ac.uk/crd), eLIBRARY.RU with Web of Science and EMBASE being unavailable for technical reasons;

- thesis and dissertation database, grey literature resources: Leiden University Repository (https:// openaccess.leidenuniv.nl), Networked Digital Library of Theses and Dissertations (http://www.ndltd. org), OpenGrey (http://www.opengrey.eu), digital dissertation library of the Russian State Library (http://diss.rsl.ru) and websites of dissertation boards of the Russian Federation and CIS countries;

- federal government websites, departments of health in the countries of interest, healthcare institutions, nongovernmental organizations involved in national and international health;

- reference lists of relevant papers to identify the key publication outlets for relevant content.

In the present review, the depth of the search was 27 years (post 1994). Outstanding books on spine surgery $[13,14]$, search filters/clinical hedges database (https://hiru.mcmaster.ca/hiru/HIRU_Hedges_home. aspx), Canadian Agency for Drugs and Technologies in Health (CADTH) database search filters (https:// www.cadth.ca/resources/finding-evidence/stringsattached-cadths-database-search-filters) and search strategies developed by surgeons [16] in nontraumatic spinal cord injuries [8] were used to make a list of search terms and phrases with the description available on the Open Science Framework (OSF) web platform at https://doi.org/10.17605/OSF.IO/5JGN4.

Inclusion criteria were the references describing organizational approaches to specialized medical care for nontraumatic spinal emergencies. Organizational approaches included medical care and costs involved. Specialized medical care was interpreted in the Federal Law No. 323-FZ revised 26.04.2016 "On the fundamentals of protection of the public health in the Russian Federation". Nontraumatic spinal emergencies were identified as a spinal disorder resulting from non-physical forces with indications to an emergency spine surgery to treat compressed nerve(s) when nonsurgical treatments haven't helped. Nontraumatic spinal emergencies can be caused by a wide spectrum of conditions including degeneration, tumors, infection and hemorrhage. Publications reporting injury to the spine, sacrum and pelvis, posttraumatic and and nontraumatic spine deformities, complications following spine surgeries, childhood and adolescence, surgical techniques, nonsurgical approaches were excluded from the search.

\section{RESULTS AND DISCUSSION}

Several aspects of the problem discussed by foreign researchers can be identified in the review. Many publications focus on how to improve primary medical care practice using medical triage system sorting patients according to treatment priority. Canadian specialists has gained a considerable experience in the matter. D.R. Fourney et al. [17] performed a systematic review of spine care pathways in the Province of Saskatchewan, Canada, and identified three defining characteristics including education on all primary care providers; calling-in nonsurgical spine specialists with special training for outpatient reception hours and nonsurgical spinal manipulations; continuous assessment of each step of the pathway. The pathway for the patient with clinical presentation potentially associated with a specific disease is as follows. The first contacting medical specialist would be a nonsurgical spine specialist like general practitioner/ family physician, physiotherapist or chiropractor. Extramural continuing medical education is available free of charge for primary care practitioners in Canada through primary care pathway programs to treat individuals presenting with spine-related concerns. The primary care practitioner identifies indications for emergency referrals to the spine surgeons. Although the authors provided no specific indications to emergency referrals N.D. Patel et al. [18] rated the appropriateness of treatment procedures for specific clinical scenarios like malignancy or infection (oncological involvement in the history, weight loss for seemingly no reason, immunosuppression, urinary infection, intravenous drug abuse, long-term use of glucocorticosteroids), suspicion of traumatic or pathological vertebral fracture (severe injury in the history, falling at home or lifting heavy things by elderly or individuals diagnosed with osteoporosis), cauda equina syndrome. Otherwise unspecified conservative care is administered for the patient, and nonresponders are supplied with referral to a nonsurgical spine clinic staffed by nonsurgical specialists specially trained for outpatient reception hours and nonsurgical spinal manipulations. These clinics reassess the classification diagnosis as well as the treatments and patients are triaged to receive further mechanical therapy, imaging, and/or referral to a spine surgeon. For nonresponders, assessment of clinical presentation can be practical using patterns of low back pain developed by $\mathrm{H}$. Hall et al. [19, 20]. Patients with back pains are referred to primary care specialist for a 6-month follow-up. Nonresponders are provided with referral to a spine surgeon. Individuals 
with leg-dominant pain and evident neurological deficiency aggravated on motion persisting for more than 6 weeks are worthy of immediate referral to a spine surgeon. Patients with intermittent signs of root irritation should be seen by a spine surgeon. Results of treatment must be documented in patient registry through the whole course of management.

G. Cutforth et al. [21], researchers at the Institute of Health Economics (http://www.ihe.ca/about/aboutihe), an independent, not-for-profit organization in the Province of Alberta, Canada, described the development of a primary-care clinical practice guideline for non-specific low back pain responsive to the Alberta context in line with the Alberta Health Technology Assessment Ambassador Program.Cauda equina syndrome was identified as an indication to immediate (within several hours) hospitalization. Nontraumatic indications to emergency admission (within 24-48 hours) included progressive intense pain aggravating at night or by lying, weight loss for seemingly no reason, oncological involvement in the history, fever, use of glucocorticosteroids) or intravenous drug abuse. Indications to delayed admission (within several weeks) included the first episode of the manifestations in individuals over 50 years and long-term moderate neurological disorders. The authors reported no results on the use of the clinical practice guideline. However, there were publications reporting efficacy of the organizational arrangements in health system of Canada [22, 23]. The majority of Canadian spine surgeons were shown to be open to the involvement of nonphysician clinicians to screen patients with low back or low back-related leg pain referred for surgical assessment [24]. Alternately, the credibility can hardly be implemented in practice [25].

C.S. Wilgenbusch et al. [26] reported a co-ordinated multidisciplinary pathway with a stratified approach to low back pain assessment and care providing a greater proportion of surgery candidates than the conventional referral process. D.R. Kindrachuk et al. [27] reported significantly reduced MRI utilization and unnecessary referrals to surgical consultants. In the United States, the majority of individuals with spine diseases requiring medical evaluation seek help through the primary care system rather than in inpatient settings [28]. There were also attempts to arrange a hospital-based standardized spine care pathway through establishing community-based health care facilities. Acute Care Jordan Hospital a 160-bed community-based hospital in Southeastern Massachusetts, serving a population of approximately 260000 people, established in Plymouth, Massachusetts in 2009 implemented an outpatient program within our hospital that followed a multidisciplinary, team-based, standardized clinical approach to the management of spinal disorders with providers from the disciplines of occupational health, neurosurgery, pain management, physical therapy as well as primary care specialists. Results for the patients treated by doctors of chiropractic were mean of 5.2 visits, mean cost per case of USD302, and $95 \%$ of patients rated their care as "excellent" [29]. Stratified care was shown to provide a cost-effective use of resources for patients with spinal disorders by primary care specialists in the United Kingdom and Western Europaen countries [30]. Extended scope of practice in nursing and physiotherapy was offered in health system in the UK. An evaluation of a spinal orthopaedic triage service in the third largest spinal unit in the UK was performed at the Nottingham University Hospitals NHS Trust. A retrospective service evaluation spanning 2012 to 2014 was undertaken by members of the extended scope practitioner (ESP) team to evaluate the ESPs' ability to manage patient care independently and triage surgical referrals appropriately. A total of 2651 patients were seen. Only $8 \%$ required either a discussion with a surgeon to confirm management or for surgical review. Of the latter, $81 \%$ were considered to be suitable surgical referrals. A $99 \%$ satisfaction rate was reported by discharged patients. ESP services in a specialist spinal service are effective in managing spinal conditions conservatively and identifying surgical candidates appropriately [31, 32]. National Clinical Lead for Spinal Services supports many of the improvements in spinal care through the use of specialist spinal triage practitioners across the UK [33]

In Australia like in many study countries, the majority of primary care management for low back pain $(98 \%)$ in large cities is provided by general medical practitioners, physiotherapists, and chiropractors without requiring an orthopaedic surgeon consultation [34]. There is a model of a physiotherapy-led triage clinic set up at a Melbourne tertiary teaching hospital administered by Austin Health to reduce waiting times for orthopaedic outpatient appointments in a public hospital [35]. Non-traumatic spinal cord injury patients were shown to be much less likely to be admitted into a specialist spinal cord injury rehabilitation unit $(30.5 \%)$ in Australia compared with traumatic spinal cord injury patients $(70.4 \%)$ [36].

Overuse of medical interventions, such as MRI requested for spinal conditions, is a considerable problem, leading to excess costs and adverse outcomes. In May 2013, a group of 
Canadian researches prospectively determined the appropriateness of requests for MRI studies at the University of Alberta Hospital (UAH) in Edmonton, Alberta, Canada (http://www.albertahealthservices. ca/assets/about/publications/ahs-pub-2015-2016annual-report.pdf), and the Ottawa Hospital (TOH) in Ottawa, Ontario, Canada (https://www. ottawahospital.on.ca/wps/portal/Base/TheHospital/ AboutOurHospital/Statistics), tertiary-level and specialty care hospitals housing 680 and 1122 beds, respectively. They prospectively identified outpatient requisitions for MRI scans at the UAH from May 2008 to September 2009 and TOH from September 2008 to March 2010. From 500 lumbar spine requisitions collected at each of the hospitals, 207 and 236 (41.4 and $47.2 \%$ ) requests were considered appropriate, 164 and 121 (32.8 and $24.2 \%$ ) were considered inappropriate, and 129 and 143 (25.8 and $28.6 \%$ ) were of uncertain value. Family physicians had a lower rate of appropriate MRI ordering for the low back than neurologists and neurosurgeons, and MRI scans ordered by neurologists and orthopedic surgeons were appropriate at nearly the same rate as with other specialties [37]. F.M. Kovacs et al. [38] reported the percentage of lumbar spine MR imaging (LSMRI) as inappropriately prescribed in routine practice being higher while the authors of other series [39] did not share the opinion. Inappropriate physical examination of patiemnts with spinal conditions prior to MRI referrals was reported by J.J. You et al. [40]. Of the 373 patients who had a cervical or lumbosacral MRI scan ordered by a primary care physician, $80.0 \%$ had no characterization of pain. Important challenges in data completeness and utility from acute care admission to community care discharge were identified by S.J. Guilcher et al. [41]. Effect of governmental intervention on appropriateness of lumbar MRI referrals was explored by S.A. Kennedy et al. [42]. In 2012, the Ontario government attempted to reduce inappropriate lumbar MRI referrals through guideline and decision-aid distributions to physicians as well as threats of financial penalties. With the policy changed at three specialized hospitals of McMaster University (Hamilton, Ontario) appropriateness of lumbar MRI referrals increased from $50.4 \%$ between January and March 2012 to $62.6 \%$ between August 2012 to September 2013 with inappropriateness of lumbar MRI referrals decreased from $47.9 \%$ to $37.1 \%$ based on the indication criteria established by the American College of Radiology (ACR). The mean appropriateness score offered by the ACR increased significantly from 5.08 to $5.79(\mathrm{P}=0.004)$ after the policy change with no significant difference in the number of new lumbar MRI referrals for lumbadynia before $(246 \pm 20.1$ per month) and after (232.7 \pm 38.3 per month) the policy change $(\mathrm{P}>0.05)$. MRI referrals for acute spinal conditions were $18.5 \%$ constituting $15.2 \%$ before and $21.7 \%$ after government intervention. J.A. Flug [43] commented that although changes in the appropriateness of MRI referrals were shown to be statistically significant they might have no clinical relevance since ACR Appropriateness Criteria for low back pain imaging terms them as "may be appropriate'. The Author's Reply featured agreement with the above comment concentrating again on the absence of decrease in the total number of MRI scans performed after government intervention [44].

In 2012, the reported imaging use data in the USA indicated to use of radiography in $12.0 \%$ to $32.2 \%$ of patients with low back pain, magnetic resonance imaging (MRI) was used in $16.0 \%$ to $21.0 \%$, computed tomography (CT) was used in $1.4 \%$ to $3.0 \%$, and MRI and/or CT was used in $10.9 \%$ to $16.1 \%$ in commercial health plans. Findings in Medicare populations were $22.9 \%$ to $48.2 \%$ for radiography, $11.6 \%$ for MRI, and $10.4 \%$ to $16.3 \%$ for MRI and/or CT [45]. The monthly mean rate of spine X-ray studies showed a $5.26 \%$ $(p=0.01)$ decrease after web-based dissemination of a diagnostic imaging guideline on the use of spine $\mathrm{X}$-ray images among chiropractors [46].

The optimal ratio between costs and effectiveness of different spinal stabilization procedures is essential for and patients with spinal conditions. Common surgical spine stabilization procedures show geographic variations in actual costs throughout the United States [47]. A retrospective cohort study involving 707951 patients who underwent any neurosurgical procedure from 2005 to 2010 and were registered in National Inpatient Sample (NIS) showed significant disparities in the fusion rate among different states which ranged from $41 \%$ in Maine to $62 \%(\mathrm{p}<0.0001)$ in Virginia with the mean rate of $53.1 \%$ across the states [48]. According to NIS, a degenerative spine disease was the main indication to surgical spine stabilization including $80.1 \%$ for anterior, $60.6 \%$ for posterior and $78.6 \%$ for combined approaches between 2001 and 2010 . Most of the surgeries constituting 96.3\%, 95.2\% and $98.1 \%$ were performed at a municipal tertiary care hospital. Combined approaches were shown to be most costly with posterior approaches involving less costs [47]. Combined approaches of surgical 
spine stabilization are associated with higher levels of healthcare expenditures involved and are superior posterior and anterior approaches in cost-effectiveness analysis according to American estimates [49].

Organization and financing of healthcare systems can be different among the countries including those in Canada and the United States explored by V.M. Taylor et al. [50]. The authors identified surgical and nonsurgical hospitalizations for back and neck problems in the administrative databases in the Province of Ontario and Washington State using the Canadian Institute for Health Information database for the 1992-1993 fiscal year (April 1992 through March 1993) and the 1992 Comprehensive Hospital Abstract Reporting System. The authors suggested that lower rates of surgery and longer lengths of stay in Ontario were associated with the Canadian universal health insurance system having access to high technology and a single payer-the provincial government. In the United States, there was a much more diverse set of payers and a growing emphasis on managed care looking at expenditures on a caseby-case basis. They likened the difference in the practice environments between the two countries to control through "fences" in Canada, where there were limits on overall but not individual expenditures, and control through "reins" in the United States, where individual services were scrutinized but where the overall expenditures and access to high-technology had been more open-ended.

Waiting times for elective (non-urgent) spinal surgery are a main health policy concern of the UK's health care system. Managing elective spine surgery patients and waiting lists is a priority for a governmentsponsored universal healthcare system called the National Health Service (NHS) that was founded in 1948. The turn of the $20^{\text {th }}$ century saw a restructuring and continued reformation of the National Health Service that resulted in changes to the waiting times standards. Department of Health reported reduction in mean waiting times for elective spinal procedure from 18 months in 1997 to less than 8 months in 2004 across the UK with the proportion of patients waiting less than 18 weeks for their elective care being at least $90 \%$ in 2008 [51]. The guiding principles were established in 2009 in the NHS constitution that set out rights to which patients, public and staff were entitled, and pledges which the NHS was committed to achieve. The recent version was published in 2019 stating the rules for ensuring patients' referral to treatment waiting time, for consultant-led treatment, is consistent within an 18-week period and withing a 2-week period with suspicion of spinal malignancy [52]. In 2016, the NHS target was for $92 \%$ of patients to be treated within 18 weeks of referral in 2020 [53]. NHS developed rules and guidance a referral to treatment data collection in 2006 [54]. The percentage of admitted patients treated within 18 weeks for non-urgent trauma and orthopaedic conditions was 86.5 and $87.9 \%$, and 85.4 and $88.4 \%$ for elective neurosurgery conditions through 2009 and 2010 [55, 56]. The national 18 weeks performance standards for admitted patients were $64.1 \%$ for elective trauma and orthopaedic procedures and $66.2 \%$ for elective neurosurgries at the end of April 2020 [57]. In August 2019, the proportion of patients waiting less than 18 weeks for their elective care cannot be representative due to COVID-19 pandremia and varied between 83.0 and $79.1 \%$ across the clinical groups [58] indicating to the underperformance of orthopaedic service targets. As mentioned in the NHS reports, there are many issues surrounding the organization of spinal services that need to be addressed to ensure that the right range of services are available for patients and that these services are clinically robust and easily accessible for both elective and emergency care $[33,59,60]$. The $3 \mathrm{~d}$ version of the last document published in 2019 takes a detailed look at the national picture in terms of the use of specialist spinal triage practitioners, clinical practice guidelines for patients with low back pain (2009) and ischialgia (2016), recommendations for Department of Health and affiliated bodies in specialized and non-specialized care prescribed in 2010 and 2016 aimed at supporting commissioners in the delivery of high quality spinal services and meeting key national waiting time standards, with the need to develop better care pathways and regional clinical networks (2010) for optimization of spine care [33].

The role of specialized surgical spine units and centers is underestimated.

To facilitate delivery of best practice treatment, specialized surgical spine centers are supposed to be a formal part of all major trauma networks to address traumatic and nontraumatic spine injury, with locally agreed protocols relating to the transfer and treatment of patients (as featured by the UK Department of Health). The findings of foreign systemic reviews have shown no evidence to support the statement [61]. The main cause for this is that the majority of patients delivered at a specialized surgical spine center are those suffering from spinal cord injuries (SCI) [62]. There is some evidence that early transfer of patients with traumatic SCI to an integrated multidisciplinary 
specialized center of care can reduce associated costs involved due to accurate indications to surgical treatment [63] and decrease overall mortality, and the number and severity of complications [63].

In Italy, patients with SCI and associated neurological deficiency can be transferred to two different types of facilities: unipolar and bilopar spinal units. Unipolar Spinal Unit is located in hospitals that are level II emergency departments with the specialists from surgery to rehabilitation with available CT and MRI and multidisciplinary approach in both the early and the rehabilitative phase for nerve and vascular involvement. In 2015, there were 17 unipolar spinal units in the country with 16 of them located in the northern part of Italy. The emergency treatments, such as the clinical and radiological assessment, and the surgery are performed at a bipolar spinal unit. After the first phase is completed, and a clinical stability is reached, the patient moves to another centre for rehabilitation. However, despite cooperative efforts, there might be some difficulties related to the fact that the two parts of the multidisciplinary treatment are held at two different places [65]. There is an increased number of emergency surgical interventions performed for both SCI and acute nontraumatic spinal pathology at tertiary hospitals in Germany [66]. One-stage treatment using minimally invasive spine surgery for spine stabilization is the preferred option of neurosurgeons and orthopaedic surgeons to treat spinal infection $[67,68,69]$. Outpatient endoscopic decompression surgery can be offered for degenerative spine diseases to ensure successful clinical outcomes [70, 71, 72]. French colleagues also reported on the increasing ambulatory practice of spinal decompression surgeries for degenerative spine diseases [73].

National Spine Registers have been established in Sweden and several countries under study to track the experiences and outcomes of people with disorders of the entire spinal column during their journey through acute care, rehabilitation and community reintegration to establish risk-adjusted national benchmarks for cost and quality for common procedures encouraging surgeons to assist in the collection of clinical data [74]. More than 75000 surgically treated patients were registered in 2012 with an increasing number yearly [75]. Several researchers found a lack of evidence that registries have had an impact on the quality of spine care, regardless of whether intervention was non-surgical and/or surgical [76, 77].

\section{CONCLUSION}

Literature review showed numerous examples of local providers and health systems of economically advanced countries working together and in different ways to improve the quality and effectiveness of spinal care. Health systems vary widely in performance, and countries with similar levels of income, education and health expenditure differ in their ability to attain key health goals. Healthcare systems are built on the tremendous progress that has been made in global health over the past 20 years. Primary health care has been central to governmental policies and strategies with a frequent focus of attention for a spinal orthopaedic triage service. The approach is an opportunity to optimise efforts and resources toward appropriate funding, logistic support and co-ordinating the spinal workforce and services. The development scenario should focus attention on ways in which primary care models and policies at a local level may need to be strengthened to meet new challenges in availability of medical expertise, building a culture, even when current arrangements are seen as effective. A convincing and operational framework set up in western countries is essential for establishing a consistent approach to deriving the definitive diagnosis of a spinal condition. The delivery of specialised spinal services requires the involvement of the full multidisciplinary team acting with the support of many other disciplines and allied health care professionals. Despite the substantial volume of research performed a number of questions on organization of specialised spinal services has remained unanswered and there is a need for further investigations in order to establish clinical guidelines considering the experiences to help support implementation of locally adapted circumstances.

The authors declare that there is no conflict of interest.

Funding: The authors - governmental assignment of the Ministry of Health of the Russian Federation (registration No. with EGISU NIOKTR: AAAA-A18-118070690080-0). 


\section{REFERENCES}

1. Noonan V.K., Wolfe D.L., Thorogood N.P., Park S.E., Hsieh J.T., Eng J.J.; SCIRE Research Team. Knowledge translation and implementation in spinal cord injury: a systematic review. Spinal Cord, 2014, vol. 52, no. 8, pp. 578-587. DOI: 10.1038/sc.2014.62

2. Burns A.S., O'Connell C. The challenge of spinal cord injury care in the developing world. J. Spinal Cord Med., 2012, vol. 35, no. 1, pp. 3-8. DOI: 10.1179/2045772311Y.0000000043

3. Haldeman S., Nordin M., Outerbridge G., Hurwitz E.L., Hondras M., Brady O., Kopansky-Giles D., Ford T., Acaroğlu E. Creating a sustainable model of spine care in underserved communities: the World Spine Care (WSC) charity. Spine J., 2015, vol. 15, no. 11, pp. 2303-2311. DOI: 10.1016/j.spinee.2015.06.046

4. New P.W., Cripps R.A., Bonne Lee B. Global maps of non-traumatic spinal cord injury epidemiology: towards a living data repository. Spinal Cord, 2014, vol. 52, no. 2, pp. 97-109. DOI: 10.1038/sc.2012.165

5. Charlifue S., Tate D., Biering-Sorensen F., Burns S., Chen Y., Chun S., Jakeman L.B., Kowalski R.G., Noonan V.K., Ullrich P. Harmonization of databa ses: a step for advancing the knowledge about spinal cord injury. Arch. Phys. Med. Rehabil., 2016, vol. 97, no. 10, pp. 1805-1818. DOI: 10.1016/j.apmr.2016.03.030

6. New P.W., Delafosse V. What to call spinal cord damage not due to trauma? Implications for literature searching. J. Spinal Cord Med., 2012, vol. 35, no. 2, pp. 89-95. DOI: 10.1179/2045772311Y.0000000053

7. Dagenais S., Caro J., Haldeman S. A systematic review of low back pain cost of illness studies in the United States and internationally. Spine J., 2008, vol. 8, no. 1, pp. 8-20. DOI: 10.1016/j.spinee.2007.10.005

8. Wu A., March L., Zheng X., Huang J., Wang X., Zhao J., Blyth F.M., Smith E., Buchbinder R., Hoy D. Global low back pain prevalence and years lived with disability from 1990 to 2017: estimates from the Global Burden of Disease Study 2017. Ann. Transl. Med., 2020, vol. 8, no. 6, pp. 299. DOI: 10.21037/atm.2020.02.175

9. World Economic Situation and Prospects 2016: Global Economic Outlook. United Nations, New York, 2016. 209 p. URL:https:// www.un.org/en/development/desa/policy/wesp/wesp_current/2016wesp_full_e.pdf (accessed 19 June 2016)

10. World Bank List of Economies (July 2015). URL: http://web.archive.org/web/20160512174732/http://siteresources.worldbank.org/ DATASTATISTICS/Resources/CLASS.XLS (accessed 19 June 2016)

11.Tricco A.C., Lillie E., Zarin W., O’Brien K.K., Colquhoun H., Levac D., Moher D., Peters M.D.J., Horsley T., Weeks L., Hempel S., Akl E.A., Chang C., McGowan J., Stewart L., Hartling L., Aldcroft A., Wilson M.G., Garritty C., Lewin S., Godfrey C.M., Macdonald M.T., Langlois E.V., Soares-Weiser K., Moriarty J., Clifford T., Tunçalp Ö., Straus S.E. PRISMA Extension for Scoping Reviews (PRISMA-ScR): checklist and explanation. Ann. Intern. Med., 2018, vol. 169, no. 7, pp. 467-473. DOI: 10.7326/M18-0850

12.Rethlefsen M., Kirtley S., Waffenschmidt S., Ayala A., Moher D., Page M., Koffel J. PRISMA-S: an extension to the PRISMA statement for reporting literature searches in systematic reviews (Version 5). OSF Preprints, 2019, 37 p. DOI: 10.31219/osf.io/sfc38

13.Herkowitz H.N., Garfin S.R., Eismont F.J., Bell G.R., Balderston R.A. Rothman Simeone The Spine. $6^{\text {th }}$ Ed. In 2 Vol. H. Philadelphia: Saunders, 2011. $2096 \mathrm{p}$.

14.Benzel E.C., Editor. Spine surgery: Techniques, Complication Avoidance and Management (Expert Consult - Online and Print). $3^{\text {rd }}$ Ed. In 2 Vol. Philadelphia, Saunders, 2012. 2248 p.

15.Campbell S. What is the difference between a filter and a hedge? Journal of EAHIL, 2016, vol. 12, no. 1, pp. 4-5.

16.Schmidt C. Surgery (general terms) - keywords. PubMed Search Strategies. 2011. URL: http://pubmedsearches.blogspot.ru/2011/05/ surgery-general-terms-keywords.html (accessed 20 June 2020)

17.Fourney D.R., Dettori J.R., Hall H., Härtl R., McGirt M.J., Daubs M.D. A systematic review of clinical pathways for lower back pain and introduction of the Saskatchewan Spine Pathway. Spine, 2011, vol. 36, no. 21 Suppl., pp. S164-S171. DOI: 10.1097/ BRS.0b013e31822ef58f

18.Patel N.D., Broderick D.F., Burns J., Deshmukh T.K., Fries I.B., Harvey H.B., Holly L., Hunt C.H., Jagadeesan B.D., Kennedy T.A., O'Toole J.E., Perlmutter J.S., Policeni B., Rosenow J.M., Schroeder J.W., Whitehead M.T., Cornelius R.S., Corey A.S. ACR appropriateness criteria: low back pain. J. Am. Coll. Radiol., 2016, vol. 13, no. 9, pp. 1069-1078. DOI: 10.1016/j.jacr.2016.06.008

19.Hall H., McIntosh G., Melles T. A different approach to back pain diagnosis: identifying a pattern of pain. Can. J. Contin. Med. Educ., 1994, vol. 6, no. 1, pp. 31-42.

20.Hall H., McIntosh G., Boyle C. Effectiveness of a low back pain classification system. Spine J., 2009, vol. 9, no. 8, pp. 648-657. DOI: $10.1016 /$ j.spinee.2009.04.017

21.Cutforth G., Peter A., Taenzer P. The Alberta Health Technology Assessment (HTA) Ambassador Program: the development of a contextually relevant, multidisciplinary clinical practice guideline for non-specific low back pain: a review. Physiother. Can., 2011, vol. 63, no. 3, pp. 278-286. DOI: 10.3138/ptc.2009-39P

22.Loisel P., Lemaire J., Poitras S., Durand M.J., Champagne F., Stock S., Diallo B., Tremblay C. Cost-benefit and cost-effectiveness analysis of a disability prevention model for back pain management: a six year follow up study. Occup. Environ. Med., 2002 , vol. 59, no. 12, pp. 807-815. DOI: 10.1136/oem.59.12.807

23.Bishop P.B., Wing P.C. Knowledge transfer in family physicians managing patients with acute low back pain: a prospective randomized control trial. Spine J., 2006, vol. 6, no. 3, pp. 282-288. DOI: 10.1016/j.spinee.2005.10.008

24.Busse J.W., Riva J.J., Nash J.V., Hsu S., Fisher C.G., Wai E.K., Brunarski D., Drew B., Quon J.A., Walter S.D., Bishop P.B., Rampersaud R. Surgeon attitudes toward nonphysician screening of low back or low back-related leg pain patients referred for surgical assessment: a survey of Canadian spine surgeons. Spine, 2013, vol. 38, no. 7, pp. E402-E408. DOI: 10.1097/BRS. 0b013e318286c96b

25.Côté P., Clarke J., Deguire S., Frank J.W., Yassi A. Chiropractors and return-to-work: the experiences of three Canadian focus groups. J. Manipulative Physiol. Ther., 2001, vol. 24, no. 5, pp. 309-316. DOI: 10.1067/mmt.2001.115267

26.Wilgenbusch C.S., Wu A.S., Fourney D.R. Triage of spine surgery referrals through a multidisciplinary care pathway: a valuebased comparison with conventional referral processes. Spine, 2014, vol. 39, no. 22 Suppl. 1, pp. S129-S135. DOI: 10.1097/ BRS.0000000000000574

27.Kindrachuk D.R., Fourney D.R. Spine surgery referrals redirected through a multidisciplinary care pathway: effects of nonsurgeon triage including MRI utilization. J. Neurosurg. Spine, 2014, vol. 20, no. 1, pp. 87-92. DOI: 10.3171/2013.10.SPINE13434

28.Videman T., Battié M.C. Commentary: back pain epidemiology - the challenge of case definition and developing new ideas. Spine J., 2012, vol. 12, no. 1, pp. 71-72. DOI: 10.1016/j.spinee.2011.12.007

29.Paskowski I., Schneider M., Stevans J., Ventura J.M., Justice B.D. A hospital-based standardized spine care pathway: report of a multidisciplinary, evidence-based process. J. Manipulative Physiol. Ther., 2011, vol. 34, no. 2, pp. 98-106. DOI: 10.1016/j. jmpt.2010.12.004 
30.Whitehurst D.G., Bryan S., Lewis M., Hay E.M., Mullis R., Foster N.E. Implementing stratified primary care management for low back pain: cost-utility analysis alongside a prospective, population-based, sequential comparison study. Spine, 2015, vol. 40, no. 6, pp. 405-414. DOI: 10.1097/BRS.0000000000000770

31.Wood L., Hendrick P., Boszczyk B., Dunstan E. A review of the surgical conversion rate and independent management of spinal extended scope practitioners in a secondary care setting. Ann. R. Coll. Surg. Engl., 2016, vol. 98, no. 3, pp. 187-191. DOI: 10.1308/ rcsann.2016.0054

32.Dunstan E., Wood L. The utility of ESP triage in a specialist secondary care spinal centre: a service evaluation. Manual Therapy, 2016, vol. 25, pp. e115-e116. DOI: 10.1016/ j.math.2016.05.209

33.Hutton M. Spinal services: GIRFT Programme National Specialty Report. London, 2019. URL: https://www.researchgate.net/ publication/330912858 www. GettingItRightFirstTime.co.uk/wp-content/uploads/2019/01/Spinal-Services-Report-Mar19-L1.pdf (accessed 21 June 2020)

34.McLain R.F. Prospective cohort study: Serious pathology in people presenting to primary care with acute low back pain is rare (0.9\%), but high false-positive rates for some 'red flags' may limit their diagnostic value. Evid. Based Med., 2010, vol. 15, no. 2, pp. 61-62. DOI: 10.1136/ebm1040

35.Blackburn M.S., Cowan S.M., Cary B., Nall C. Physiotherapy-led triage clinic for low back pain. Aust. Health Rev., 2009, vol. 33, no. 4, pp. 663-670. DOI: 10.1071/ah090663

36.New P.W., Simmonds F., Stevermuer T. Comparison of patients managed in specialised spinal rehabilitation units with those managed in non-specialised rehabilitation units. Spinal Cord, 2011, vol. 49, no. 8, pp. 909-916. DOI: 10.1038/sc.2011.29

37.Emery D.J., Shojania K.G., Forster A.J., Mojaverian N., Feasby T.E. Overuse of magnetic resonance imaging. JAMA Intern. Med., 2013, vol. 173, no. 9, pp. 823-825. DOI: 10.1001/jamainternmed.2013.3804

38.Kovacs F.M., Arana E., Royuela A., Cabrera A., Casillas C., Piñero P., Vega M., Asenjo B., Estremera A., Amengual G., Sarasíbar H., Ferrer P., Manjarrés A., Zamarro J., Bravo-Rodríguez F., Paniagua J.C., Mota J., Sánchez-Sagrado T., Abraira V., Martínez C. Appropriateness of lumbar spine magnetic resonance imaging in Spain. Eur. J. Radiol., 2013, vol. 82, no. 6, pp. 1008-1014. DOI: 10.1016/j.ejrad.2013.01.017

39.Emery D.J., Feasby T.E. Inappropriate use of lumbar magnetic resonance imaging: limitations and potential solutions-reply. JAMA Intern. Med., 2013, vol. 173, no. 21, pp. 2012-2013. DOI:10.1001/jamainternmed.2013.9956

40.You J.J., Bederman S.S., Symons S., Bell C.M., Yun L., Laupacis A., Rampersaud Y.R. Patterns of care after magnetic resonance imaging of the spine in primary care. Spine, 2013, vol. 38, no. 1, pp. 51-59. DOI: 10.1097/BRS.0b013e3182611182

41.Guilcher S.J., Parsons D., Craven B.C., Jaglal S.B., Verrier M. Developing quality of care indicators for patients with traumatic and non-traumatic spinal cord injury (SCI): a feasibility study using administrative health data. J. Spinal Cord Med., 2015, vol. 38, no. 6, pp. 765-776. DOI: 10.1179/2045772315Y.0000000043

42.Kennedy S.A., Fung W., Malik A., Farrokhyar F., Midia M. Effect of governmental intervention on appropriateness of lumbar MRI referrals: a Canadian experience. J. Am. Coll. Radiol., 2014, vol. 11, no. 8, pp. 802-807. DOI: 10.1016/j.jacr.2013.12.022

43.Flug J.A. Re: "Effect of governmental intervention on appropriateness of lumbar MRI referrals: a Canadian experience". J. Am. Coll. Radiol., 2015, vol. 12, no. 2, pp. 208-209. DOI: 10.1016/j.jacr.2014.08.026

44.Kennedy S.A., Midia M. Authors' reply. J. Am. Coll. Radiol., 2015, vol. 12, no. 2, pp. 209. DOI: 10.1016/j.jacr.2014.11.007

45.Dagenais S., Galloway E.K., Roffey D.M. A systematic review of diagnostic imaging use for low back pain in the United States. Spine J., 2014, vol. 14, no. 6, pp. 1036-1048. DOI: 10.1016/j.spinee.2013.10.031

46.Bussières A.E., Sales A.E., Ramsay T., Hilles S.M., Grimshaw J.M. Impact of imaging guidelines on X-ray use among American provider network chiropractors: interrupted time series analysis. Spine J., 2014, vol. 14, no. 8, pp. 1501-1509. DOI: 10.1016/j. spinee.2013.08.051

47.Goz V., Rane A., Abtahi A.M., Lawrence B.D., Brodke D.S., Spiker W.R. Geographic variations in the cost of spine surgery. Spine, 2015, vol. 40, no. 17, pp. 1380-1389. DOI: 10.1097/BRS.0000000000001022

48.Bekelis K., Missios S. The association of regional intensity of neurosurgical care with spinal fusion surgery in the USA. Eur. Spine J., 2014, vol. 23, no. 4, pp. 909-915. DOI: 10.1007/s00586-014-3201-6

49.Ghogawala Z., Whitmore R.G., Watters W.C. 3rd, Sharan A., Mummaneni P.V., Dailey A.T., Choudhri T.F., Eck J.C., Groff M.W., Wang J.C., Resnick D.K., Dhall S.S., Kaiser M.G. Guideline update for the performance of fusion procedures for degenerative disease of the lumbar spine. Part 3: assessment of economic outcome. J. Neurosurg. Spine, 2014, vol. 21, no. 1, pp. 14-22. DOI: 10.3171/2014.4.SPINE14259

50.Taylor V.M., Anderson G.M., McNeney B., Diehr P., Lavis J.N., Deyo R.A., Bombardier C., Malter A., Axcell T. Hospitalizations for back and neck problems: a comparison between the Province of Ontario and Washington State. Health Serv. Res., 1998, vol. 33, no. 4, Pt. 1, pp. 929-945

51. The NHS Improvement Plan: Putting People at the Heart of Public Services. Great Britain, Department of Health, The Stationery Office. 2004. 80 p. URL: http://www.dh.gov.uk/prod_consum_dh/groups/dh_digitalassets/@dh/@en/@ps/documents/digitalasset/dh_118572. pdf (accessed 19 June 2020)

52. Guidance Handbook to the NHS Constitution for England. Information about the rights and pledges in the NHS Constitution and What these mean for NHS patients and staff. England, Department of Health and Social Care, Public Health England, 2019. URL: https://www.gov.uk/government/publications/supplements-to-the-nhs-constitution-for-england/the-handbook-to-the-nhsconstitution-for-england (accessed 16 June 2020)

53. The Government's mandate to NHS England for 2016-17. A mandate from the Government to NHS England: April 2016 to March 2017. Presented to Parliament pursuant to Section 13A(1) of the National Health Service Act 2006. UK Department of Health, 2016. URL: https://assets.publishing.service.gov.uk/government/uploads/system/uploads/attachment_data/file/600604/NHSE_ Mandate 2016-17.pdf (accessed 19 June 2020)

54. Developing a referral to treatment data collection. Rules and guidance. Patient's rights and the guide to NHS waiting times. RTT rules suite. UK Department of Health, 2007. URL: http://www.dh.gov.uk/prod_consum_dh/groups/dh_digitalassets/@dh/@en/ documents/digitalasset/dh_089768.doc (accessed 19 June 2020)

55. NHS Referral to Treatment (RTT) Waiting Times Statistics for England: 2009 annual report. UK Department of Health, 2009. URL: http:// www.dh.gov.uk/prod_consum_dh/groups/dh_digitalassets/@dh/@en/@ps/@sta/@perf/documents/digitalasset/dh_112663. pdf (accessed 19 June 2020)

56. NHS Referral to Treatment (RTT) Waiting Times Statistics for England: 2010 annual report. UK Department of Health, 2010. URL: http:// https://assets.publishing.service.gov.uk/government/uploads/system/uploads/attachment_data/file/216500/dh_124441. pdf (accessed 21 June 2020) 
57. Consultant-led Referral to Treatment Waiting Times Data 2020-21. April 2020. NHS England and NHS Improvement: monthly RTT data collection, 2020. URL: https://www.england.nhs.uk/statistics/wp-content/uploads/sites/2/2020/06/Apr20-RTT-SPN-publication-version. pdf (accessed 16 June 2020)

58.Statistical Press Notice NHS referral to treatment (RTT) waiting times data, August 2019. URL: https://www.england.nhs.uk/ statistics/wp-content/uploads/sites/2/2019/10/Aug19-RTT-SPN-publication-version.pdf (accessed 16 June 2020)

59. Organising quality and effective spinal services for patients: a report for local health communities by the Spinal Taskforce. UK Spinal Taskforce, 2010. Version 1. DH Gateway Ref. 13885. URL: https://ba17bc65-2f2f-4a2f-9427-cd68a3685f52.filesusr.com/ ugd/dd7c8a_3a66cbfb28724a6cb774ca362d12efe8.pdf (accessed 19 June 2020)

60. Commissioning spinal services - getting the service back on track. A guide for commissioners of spinal services. UK Spinal Taskforce, 2013. URL: https://ba17bc65-2f2f-4a2f-9427-cd68a3685f52.filesusr.com/ugd/dd7c8a_c5075daa95274f1eb8b311bb74d2c1f7.pdf (accessed 19 June 2020)

61.Maharaj M.M., Hogan J.A., Phan K., Mobbs R.J. The role of specialist units to provide focused care and complication avoidance following traumatic spinal cord injury: a systematic review. Eur. Spine J., 2016, vol. 25, no. 6, pp. 1813-1820. DOI: 10.1007/ s00586-016-4545-x

62.Zárate-Kalfópulos B., Jiménez-González A., Reyes-Sánchez A., Robles-Ortiz R., Cabrera-Aldana E.E., Rosales-Olivarez L.M. Demographic and clinical characteristics of patients with spinal cord injury: a single hospital-based study. Spinal Cord, 2016, vol. 54, no. 11, pp. 1016-1019. DOI: 10.1038/sc.2016.41

63.Viola D.C., Lenza M., Almeida S.L., Santos O.F., Cendoroglo Neto M., Lottenberg C.L., Ferretti M. Spine surgery cost reduction at a specialized treatment center. Einstein (Sao Paulo), 2013, vol. 11, no. 1, pp. 102-107. DOI: 10.1590/s1679-45082013000100018

64.Parent S., Barchi S., LeBreton M., Casha S., Fehlings M.G. The impact of specialized centers of care for spinal cord injury on length of stay, complications, and mortality: a systematic review of the literature. J. Neurotrauma, 2011, vol. 28, no. 8, pp. $1363-1370$. DOI: 10.1089/neu.2009.1151

65.Landi A., Gregori F., Delfini R. Spinal trauma in Italy: actuality and future perspectives. Orthop. Muscular Syst., 2015, vol. 4, pp. e118. DOI: 10.4172/2161-0533.1000e118

66.Kreinest M., Ludes L., Türk A., Grützner P.A., Biglari B., Matschke S. Analysis of prehospital care and emergency room treatment of patients with acute traumatic spinal cord injury: a retrospective cohort study on the implementation of current guidelines. Spinal Cord, 2017, vol. 55, no. 1, pp. 16-19. DOI: 10.1038/sc.2016.84

67.Quack V., Hermann I., Rath B., Dietrich K., Spreckelsen C., Lüring C., Arbab D., Mueller C.A., Shousha M., Clusmann H., Tingart M. Aktuelle Behandlungsstrategien der Spondylodiszitis in deutschen Akutkliniken [Current treatment strategies for spondylodiscitis in surgical clinics in Germany]. Z. Orthop. Unfall., 2014, vol. 152, no. 6, pp. 577-583. (in German) DOI: 10.1055/s-0034-1383131

68.Bornemann R., Müller-Broich J.D., Deml M., Sander K., Wirtz D.C., Pflugmacher R. Diagnose und Behandlung der Spondylitis/ Spondylodiszitis in der Klinikroutine [Diagnosis and Treatment of Spondylodiscitis/Spondylitis in Clinical Practice]. Z. Orthop. Unfall., 2015, vol. 153, no. 5, pp. 540-545. (in German) DOI: 10.1055/s-0035-1546216

69.Shousha M., Heyde C., Boehm H. Cervical spondylodiscitis: change in clinical picture and operative management during the last two decades. A series of 50 patients and review of literature. Eur. Spine J., 2015, vol. 24, no. 3, pp. 571-576. DOI: 10.1007/s00586014-3672-5

70.Hofstetter C.P., Hofer A.S., Wang M.Y. Economic impact of minimally invasive lumbar surgery. World J. Orthop., 2015, vol. 6, no. 2, pp. 190-201. DOI: 10.5312/wjo.v6.i2.190

71.Basil G.W., Wang M.Y. Trends in outpatient minimally invasive spine surgery. J. Spine Surg., 2019, vol. 5, no. Suppl. 1, pp. S108-S114. DOI: $10.21037 /$ jss.2019.04.17

72.Lewandrowski K.U., Ransom N.A., Yeung A. Return to work and recovery time analysis after outpatient endoscopic lumbar transforaminal decompression surgery. J. Spine Surg., 2020, vol. 6, no. Suppl. 1, pp. S100-S115. DOI: 10.21037/jss.2019.10.01

73.Hulet C., Rochcongar G., Court C. Developments in ambulatory surgery in orthopedics in France in 2016. Orthop. Traumatol. Surg. Res., 2017, vol. 103, no. 1S, pp. S83-S90. DOI: 10.1016/j.otsr.2016.11.005

74.Strömqvist B. Evidence-based lumbar spine surgery. The role of national registration. Acta Orthop. Scand. Suppl., 2002, vol. 73, no. 305, pp. 34-39. DOI: 10.1080/000164702760379530

75.Strömqvist B., Fritzell P., Hägg O., Jönsson B., Sandén B.; Swedish Society of Spinal Surgeons. Swespine: the Swedish spine register: the 2012 report. Eur. Spine J., 2013, vol. 22, no. 4, pp. 953-974. DOI: 10.1007/s00586-013-2758-9

76. Fairbank J. Spinal disorders, quality-based healthcare and spinal registers. Acta Orthop., 2015, vol. 86, no. 5, pp. 521-522. DOI: 10.3109/17453674.2015.1072431

77.Van Hooff M.L., Jacobs W.C., Willems P.C., Wouters M.W., De Kleuver M., Peul W.C., Ostelo R.W., Fritzell P. Evidence and practice in spine registries. Acta Orthop., 2015, vol. 86, no. 5, pp. 534-544. DOI: 10.3109/17453674.2015.1043174

Received: 13.07 .2020

\section{Information about the authors:}

1.Aleksandr K. Dulaev, M.D., Ph.D., Professor,

Saint-Petersburg I.I. Dzhanelidze Research Institute of Emergency Medicine, Saint Petersburg, Russian Federation,

Pavlov First St. Petersburg State Medical University, Saint Petersburg, Russian Federation,

Email: akdulaev@gmail.com

2.Denis I. Kutianov, M.D., Ph.D., Professor,

Pavlov First St. Petersburg State Medical University, Saint Petersburg, Russian Federation,

Email:kutianov@rambler.ru

3. Pavel V. Zhelnov, M.D.,

Pavlov First St. Petersburg State Medical University, Saint Petersburg, Russian Federation,

Email: pzhelnov@p1m.org

4. Sergei L. Brizhan', M.D., Ph.D.,

Pavlov First St. Petersburg State Medical University, Saint Petersburg, Russian Federation,

Email: pmu@68gkb.ru 